\title{
The Progress of Photoluminescent Properties of Rare-Earth-Ions-Doped Phosphate One-Dimensional Nanocrystals
}

\author{
Lixin Yu and Hai Liu \\ Department of Materials Science and Engineering, Nanchang University, Nanchang 330031, China \\ Correspondence should be addressed to Lixin Yu, yulixin72@yahoo.com.cn \\ Received 5 November 2009; Accepted 3 March 2010 \\ Academic Editor: Renzhi Ma
}

Copyright ( $) 2010$ L. Yu and H. Liu. This is an open access article distributed under the Creative Commons Attribution License, which permits unrestricted use, distribution, and reproduction in any medium, provided the original work is properly cited.

\begin{abstract}
One-dimensional (1D) nanostructures, such as tubes, wires, rods, and belts, have aroused remarkable attentions over the past decade due to a great deal of potential applications, such as data storage, advanced catalyst, and photoelectronic devices . On the other hand, in comparison with zero-dimensional (0D) nanostructures, the space anisotropy of 1D structures provided a better model system to study the dependence of electronic transport, optical and mechanical properties on size confinement and dimensionality. Rare earth (RE) compounds, were intensively applied in luminescent and display devices. It is expected that in nanosized RE compounds the luminescent quantum efficiency (QE) and display resolution could be improved. In this paper, we systematically reported the research progress of luminescent properties of RE-doped $1 \mathrm{D}$ orthophosphate nanocrystal, including the synthesis of $1 \mathrm{D}$ nanostructures doped with RE ions, local symmetry of host, electronic transition processes, energy transfer (ET), and so forth.
\end{abstract}

\section{Introduction}

It is well known that the reduction of particle size of crystalline system can result in remarkable modification of their properties which are different from those of microsized hosts because of surface effect and quantum confinement effect of nanometer materials. In 1994, Bhargava et al. reported that radiative transition rate of $\mathrm{ZnS}: \mathrm{Mn}$ nanocrystals increased five orders in comparison with bulk one [1]. Although this result was strongly criticized later, the studies on nanosized luminescent semiconductor attracted great interests [2-6]. $\mathrm{RE}$ compounds were extensively applied in luminescence and display, such as lighting, field emission display (FED), cathode ray tubes (CRT), and plasma display panel (PDP) [7-11]. Lanthanide orthophosphate $\left(\mathrm{LnPO}_{4}\right)$ belongs to two polymorphic types, the monoclinic monazite type (for La to Gd) and quadratic xenotime type (for $\mathrm{Tb}$ to $\mathrm{Lu}$ ). Due to its high QE, bulk lanthanide phosphate as an ideal host in fluorescent lamps, CRT and PDP, has been extensively investigated [12-14]. It is expected that nanosized RE compounds can increase luminescent $\mathrm{QE}$ and display resolution. To improve luminescent properties of nanocrystalline phosphors, many preparation methods have been used, such as solid state reactions, sol-gel techniques, hydroxide precipitation, hydrothermal synthesis, spray pyrolysis, laser-heated evaporation, and combustion synthesis. Currently, the luminescent RE-doped 1D nanocrystals such as $\mathrm{LaPO}_{4}$ : RE nanowires [15-19], $\mathrm{Y}_{2} \mathrm{O}_{3}: \mathrm{RE}$ and $\mathrm{La}_{2} \mathrm{O}_{3}$ :Eu nanotubes/nanowires [20-25], and $\mathrm{YVO}_{4}$ : Eu nanowires/nanorods [26-28]. have also attracted considerable interests. 1D structures, such as tubes, wires, rods, and belts, have aroused remarkable attentions over past decade due to a great deal of potential applications, such as data storage [29], advanced catalyst [30], and photoelectronic devices [31]. On the other hand, in comparison with $0 \mathrm{D}$ structures, the space anisotropy of $1 \mathrm{D}$ structures provided a better model system to study the dependence of electronic transport and optical and mechanical properties on size confinement and dimensionality [32]. To develop 1D phosphors, a basic question should be answered: could the photoluminescent properties for 1D nanocrystals be improved than $0 \mathrm{D}$ ones as well as the micrometer materials, the so-called bulk materials? In this review, we concentrated 


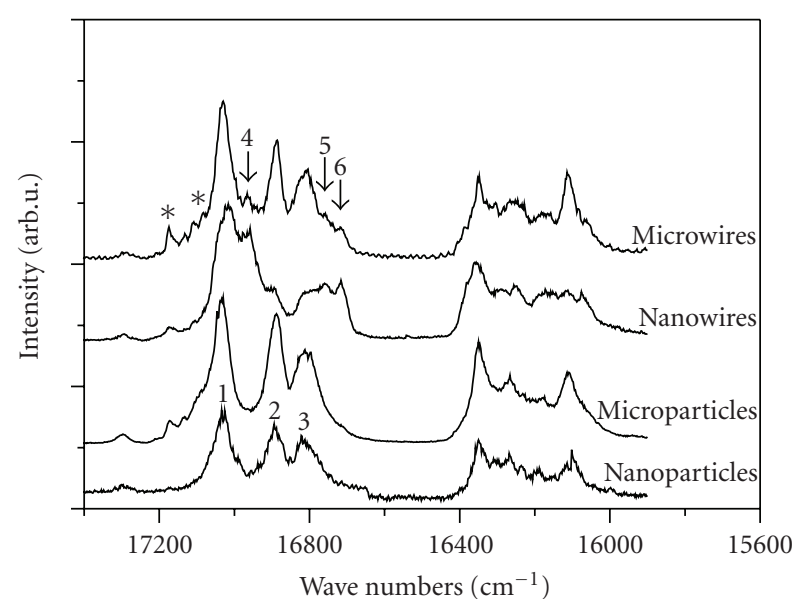

FIGURE 1: High-resolution spectra of $\mathrm{LaPO}_{4}: \mathrm{Eu}^{3+}$ bulk, nanoparticles, and nanowires at $10 \mathrm{~K}$ under $266 \mathrm{~nm}$ light excitation (delay time is $50 \mu$ s). (J. Phys. Chem. B 2004, 108, 16697; Appl. Phys. Lett. 2004, 85, 470).

on the study progress of photoluminescent properties of RE ions in phosphate 1D nanocrystals.

\section{The Synthesis of Phosphate 1D Nanocrystals Doped with RE}

In 1999, Meyssamy et al. reported the preparation of $\mathrm{LaPO}_{4}: \mathrm{Eu}^{3+} / \mathrm{Tb}^{3+}$ nanowires by a hydrothermal method and studied their luminescent properties for the first time [15]. After then, researchers prepared phosphate $1 \mathrm{D}$ nanocrystals doped with RE ions by different synthesis techniques, such as hydrothermal method to prepare $\mathrm{LaPO}_{4}: \mathrm{Ce}^{3+} / \mathrm{Eu}^{3+}$ nanofibers [33], $\mathrm{CePO}_{4}: \mathrm{Tb}^{3+}$ colloidal nanocrystals [34], $\mathrm{CePO}_{4}: \mathrm{Tb}^{3+} / \mathrm{LaPO}_{4}$ nanowires core-shell structures $[35,36]$, and $\mathrm{LnPO}_{4}(\mathrm{Ln}=\mathrm{RE})$ nanowires and nanosheets [19]. It should be noted that these reports mainly emphasize the morphology control through changing synthesis conditions. To our knowledge, although $\mathrm{LnPO}_{4} 1 \mathrm{D}$ nanocrystals doped with RE ions with different shapes were prepared by the wet chemistry method by many groups, the luminescent properties, especially electronic transition processes and ET processes, were not further studied. Our group systemically reported luminescent characteristics of $\mathrm{LnPO}_{4}: \mathrm{RE}$ ( $\mathrm{Ln}=$ $\mathrm{La}, \mathrm{Gd})$ nanowires and nanorods. Song and $\mathrm{Yu}$ et al. systemically and further investigated the $\mathrm{LaPO}_{4}: \mathrm{Eu}^{3+} / \mathrm{Tb}^{3+}$ nanowires photoluminescent properties in comparison with OD nanoparticles and bulk materials, especial electronic transition process and ET.

\section{Local Symmetry of $\mathbf{E u}^{3+}$ in $1 D$ Nanocrystals}

Because $\mathrm{Eu}^{3+}$ ions were hypersensitive to local structures, they can be used as a fluorescent probe to detect the microstructures surrounding $\mathrm{Eu}^{3+}$ ions. In previous research, the local environmental around $\mathrm{Eu}^{3+}$ ions in $0 \mathrm{D}$ nanoparticles was systematically studied. Many groups reported the appearance of additional sites of $\mathrm{Eu}^{3+}$ ions in $\mathrm{Y}_{2} \mathrm{O}_{3}$ and

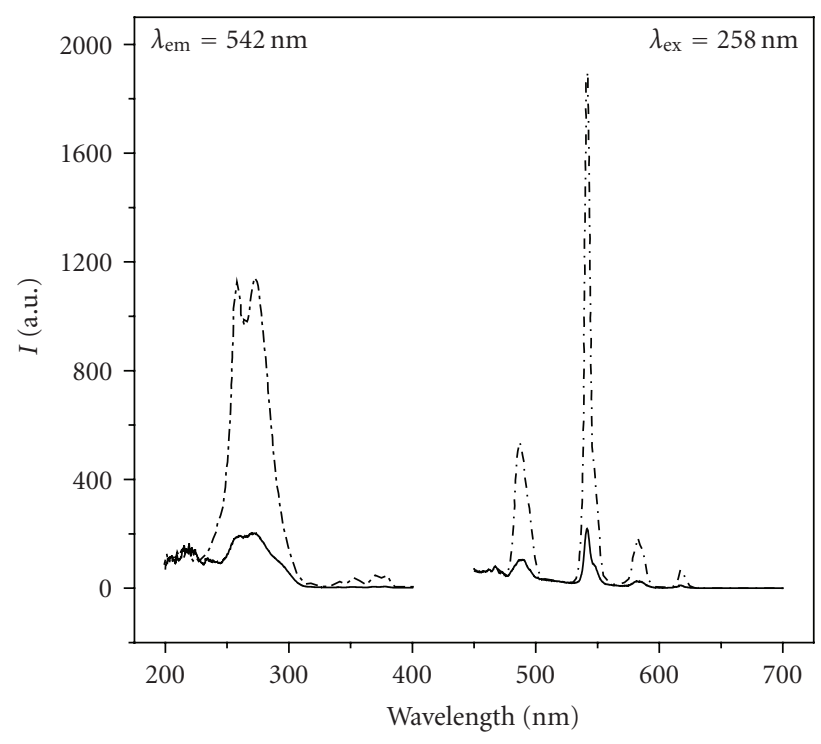

Figure 2: The excitation spectra (left) and emission. (right) for $\mathrm{LaPO}_{4}: 1 \% \mathrm{Ce}, 2.5 \% \mathrm{~Tb}$ samples. Solid lines and dash dots represented the microrods and nanowires, respectively. (J. Phys. Chem. B 2005, 109, 11450).

$\mathrm{YBO}_{3}$ nanoparticles through high-resolution spectra at low temperature [37-40]. They contributed the origin of additional sites of $\mathrm{Eu}^{3+}$ doped nanoparticles to the surface effect because the disorder of atoms at the surface of nanoparticles increased on comparison with the inside atoms. Although $\mathrm{LnPO}_{4}: \mathrm{Eu}^{3+} 1 \mathrm{D}$ nanowires/nanorods were prepared and their basic spectra were researched, the dependence of local symmetry on shape was not studied. Song and $\mathrm{Yu}$ et al. investigated the microstructures of $\mathrm{Eu}^{3+}$ doped $1 \mathrm{D} \mathrm{LaPO}_{4}$ nanowires in contrast with $0 \mathrm{D}$ nanoparticles and corresponding micrometer hosts (micrometer particles and rods) $[16,18,41]$. The $\mathrm{LaPO}_{4}$ nanoparticles, nanowires, and bulk materials were synthesized by the same synthesis technique, a hydrothermal method. All samples were at monazite phase and no additional phases were observed. The size of $\mathrm{LaPO}_{4}: \mathrm{Eu}^{3+}$ nanoparticless is ranging from 10 to $20 \mathrm{~nm}$. The diameter of $\mathrm{LaPO}_{4}: \mathrm{Eu}^{3+}$ nanowires ranges from 10 to $20 \mathrm{~nm}$, and the length is about several hundreds nanometer. They observed that the $\mathrm{Eu}^{3+}$ ions locate new site in nanowires due to shape effect. Figure 1 shows the high-resolution spectra of $\mathrm{LaPO}_{4}: \mathrm{Eu}^{3+}$ nanomaterials and bulk materials at $266 \mathrm{~nm}$ pulsed laser excitation at $10 \mathrm{~K}$. The emission associated with ${ }^{5} \mathrm{D}_{0}{ }^{7} \mathrm{~F}_{1}$ transitions is quite different between nanoparticles and nanowires at $10 \mathrm{~K}$. In the nanoparticles, three ${ }^{5} \mathrm{D}_{0}{ }^{-7} \mathrm{~F}_{1}$ emission lines were observed, locating at $17025 \pm 2 \mathrm{~cm}^{-1}$ (L1), $16898 \pm 2 \mathrm{~cm}^{-1}$ (L2), and $16815 \pm 2 \mathrm{~cm}^{-1}$ (L3), respectively. In the nanowires, besides the same lines 1-3, three additional lines 4-6 were observed, locating at 16963 $\pm 2 \mathrm{~cm}^{-1}$ (L4),16758 $\pm 2 \mathrm{~cm}^{-1}$ (L5), and $16718 \pm 2 \mathrm{~cm}^{-1}$ (L6), respectively. The ${ }^{5} \mathrm{D}_{0}{ }^{-} \mathrm{F}_{1}$ lines in the microparticles are identical with the nanoparticles. For the microrods, lines 16 were also observed. However, the relative intensity of lines 4-6 becomes weaker in comparison with that in nanowires. ${ }^{7} \mathrm{~F}_{1}$ associated with one site symmetry can split into three 
TABLE 1: A list of parameters $W_{1}, W_{10}(0)$ and the internal luminescent $\mathrm{QE}$ at $0 \mathrm{~K}$ in different powders.

\begin{tabular}{lcccc}
\hline Parameters & nanoparticles & nanowires & microparticles & microrods \\
\hline$W_{1}\left(\mathrm{~ms}^{-1}\right)$ & 14.9 & 28.9 & 17.6 & 16.5 \\
$W_{10}\left(\mathrm{~ms}^{-1}\right)$ & 24.1 & 19.7 & 17.8 & 18.5 \\
$\mathrm{QE}$ & $38 \%$ & $59 \%$ & $49 \%$ & $47 \%$ \\
\hline
\end{tabular}

Stark lines in the crystal field. The results in Figure 1 indicate that in nanoparticles and microrods, the ${ }^{5} \mathrm{D}_{0}{ }^{7} \mathrm{~F}_{1}$ transitions are from one crystalline site, $\mathrm{A}$, while in nanowires and microrods, the ${ }^{5} \mathrm{D}_{0}{ }^{7} \mathrm{~F}_{1}$ transitions come from the same site (L1-L3), A, and an additional site (L4-L6), B. The relative number of $\mathrm{Eu}^{3+}$ at site $\mathrm{B}$ decreases as the powders vary from the nanowires to the microrods. In the present case, from the microparticles to the nanoparticles, the ratio of surface to volume increases greatly, but no additional site is observed. From the microrods to the nanowires, the ratio of surface to volume do not increase so much; however, the additional site $\mathrm{B}$ appears and the relative number of $\mathrm{Eu}^{3+}$ at site $\mathrm{B}$ changes greatly. We thus believe that the appearance of the additional site B is not caused by the surface effect, but by the shape anisotropy. This is the first time to report that the shape effect affects the local structures of $\mathrm{Eu}^{3+}$ doped 1D nanocrystals.

\section{Electronic Transition Processes and QE of $\mathrm{Eu}^{3+}$ in $\mathrm{LaPO}_{4}$ 1D Nanocrystals}

In $0 \mathrm{D}$ nanoparticles, many groups reported that the $\mathrm{QE}$ and luminescent intensity of $\mathrm{Eu}^{3+}$ ions decreased in comparison with the bulk materials due to higher nonradiative transition rate in nanoparticles $[42,43]$. An important problem should be answered: does the $\mathrm{QE}$ of $\mathrm{Eu}^{3+}$ in 1D nanocrystals increase in contrast with nanoparticles and bulk materials? Song and $\mathrm{Yu}$ et al. systematically studied the electronic transition processes of $\mathrm{Eu}^{3+}$ in $\mathrm{LaPO}_{4}$ nanowires $[16,18,41]$. The luminescence $\mathrm{QE}$ of ${ }^{5} \mathrm{D}_{1}$ level of $\mathrm{Eu}^{3+}$ was determined by the following equation:

$$
\tau(T)=\frac{1}{W_{1}+W_{10}(T)},
$$

where $W 1$ is the radiative transition rate of ${ }^{5} \mathrm{D}_{1}-\sum_{J}^{7} \mathrm{~F}_{J}$, $W_{10}(T)$ is nonradiative transition rate at a certain temperature, $T$. According to the theory of multiphonon relaxation, $W_{10}$ can be written as

$$
W_{10}(T)=W_{10}(0)(1+\langle n\rangle)^{\Delta E_{10} / \hbar \omega}
$$

where $W_{10}(0)$ is nonradiative transition rate at $0 \mathrm{~K}, \Delta E_{10}$ is the energy separation between ${ }^{5} \mathrm{D}_{1}$ and ${ }^{5} \mathrm{D}_{0}$, $\hbar \omega$ is the phonon energy, $k$ is Boltzmann' constant, and $\langle n\rangle=1 /$ $\left(e^{\hbar \omega / k T}-1\right)$ is the phonon occupation number. According to (1) and (2), the lifetime of ${ }^{5} \mathrm{D}_{1}$ can be expressed as

$$
\tau=\frac{1}{W_{1}+W_{10}(0)[1-\exp (-\hbar \omega / k T)]^{-\Delta E_{10} / \hbar \omega}} .
$$

They measured the lifetime of ${ }^{5} \mathrm{D}_{1}$ level of $\mathrm{Eu}^{3+}$ ions at different temperatures and obtained the radiative and

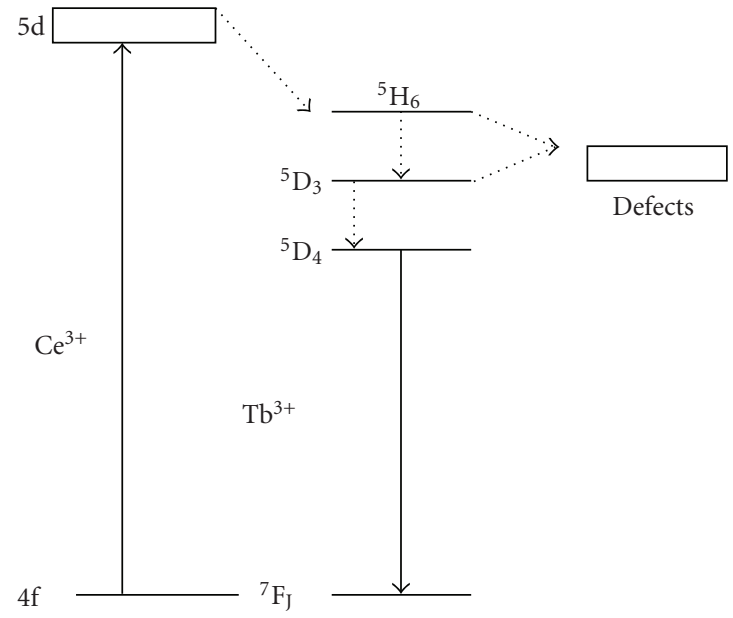

FIGURE 3: Schematic for the ET and luminescence processes in $\mathrm{Ce}^{3+} / \mathrm{Tb}^{3+}$ codoped $\mathrm{LaPO}_{4}$ nanowires and microrods. (J. Phys. Chem. B 2005, 109, 11450).

nonradiative transition rate by fitting according to (3). The results were listed in Table 1 . It is obvious that the radiative transitive rate and $\mathrm{QE}$ of ${ }^{5} \mathrm{D}_{1}$ level in nanowires were higher than that in nanoparticles and bulk crystals. This result indicates that the $1 \mathrm{D}$ nanocrystal-doped RE ions is ideal phosphors. After then, they also studied the electronic transition processes of $\mathrm{Eu}^{3+}$ ions in $\mathrm{Y}_{2} \mathrm{O}_{3}$ and $\mathrm{La}_{2} \mathrm{O}_{3}$ nanowires $[24,25]$. The results indicate that the radiative transition rate of $\mathrm{Eu}^{3+}$ in oxide nanowires hardly changes in comparison with the bulk hosts.

\section{ET between RE Ions in $\mathrm{LaPO}_{4} 1 \mathrm{D}$ Nanowires}

$\mathrm{Ce}^{3+}$ and $\mathrm{Tb}^{3+}$ ions are important $\mathrm{RE}$ ions, which have been applied in blue and green phosphors. The ET processes between $\mathrm{Ce}^{3+}$ and $\mathrm{Tb}^{3+}$ in some micrometer-sized materials, such as lanthanum oxybromide [44], aluminate [45], alkaline earth sulphate [46], and so on, were intensively investigated. As efficient green phosphors, $\mathrm{Ce}^{3+}$ and $\mathrm{Tb}^{3+}$ coactivated $\mathrm{LaPO}_{4}$ bulk powders were extensively applied to fluorescent lamps, cathode ray cube (CRT), and plasma display panel (PDP) due to the high ET efficiency between $\mathrm{Ce}^{3+}$ and $\mathrm{Tb}^{3+}$ ions [13]. To obtain the efficient green phosphors of 1D $\mathrm{LaPO}_{4}: \mathrm{Ce}^{3+} / \mathrm{Tb}^{3+}$ nanowires, the electronic transition and ET processes in 1D nanowires should be studied, and compared with the corresponding bulk powders. However, the studies on ET processes between $\mathrm{Ce}^{3+}$ and $\mathrm{Tb}^{3+}$, even between different RE impurity centers, are rather rare. Song and $\mathrm{Yu}$ et al. fabricated $\mathrm{Ce}^{3+}$ and $\mathrm{Tb}^{3+}$ coactivated $\mathrm{LaPO}_{4}$ nanowires as well as the micrometer-sized rods by the same hydrothermal method [17, 47]. They systematically studied and compared their electronic transition and ET processes by the luminescent spectra and dynamics analysis. Figure 2 shows the excitation and emission spectra of $\mathrm{LaPO}_{4}: \mathrm{Ce}^{3+}, \mathrm{Tb}^{3+}$ nanowires and microrods. It is obvious and important that the luminescent intensity of $\mathrm{Tb}^{3+}$ in $\mathrm{LaPO}_{4}: \mathrm{Ce}^{3+}, \mathrm{Tb}^{3+}$ nanowires is much stronger than that in 
TABLE 2: List of dynamic results of $\mathrm{LaPO}_{4}: 0.01 \mathrm{Ce}^{3+}, 0.025 \mathrm{~Tb}^{3+}$ nanowires and microrods.

\begin{tabular}{lccc}
\hline Samples & Electronic transition rate of $\mathrm{Ce}^{3+}\left(\mathrm{ns}^{-1}\right)$ & Lifetime of $\mathrm{Tb}^{3+}(\mathrm{ms})$ & $\mathrm{ET}\left(\mathrm{ns}^{-1} \mathrm{~mol}^{-1}\right)$ \\
\hline nanowires & $6.3 \times 10^{-2}$ & 2.72 & 0.44 \\
microrods & $5.2 \times 10^{-2}$ & 2.58 & 1.30
\end{tabular}

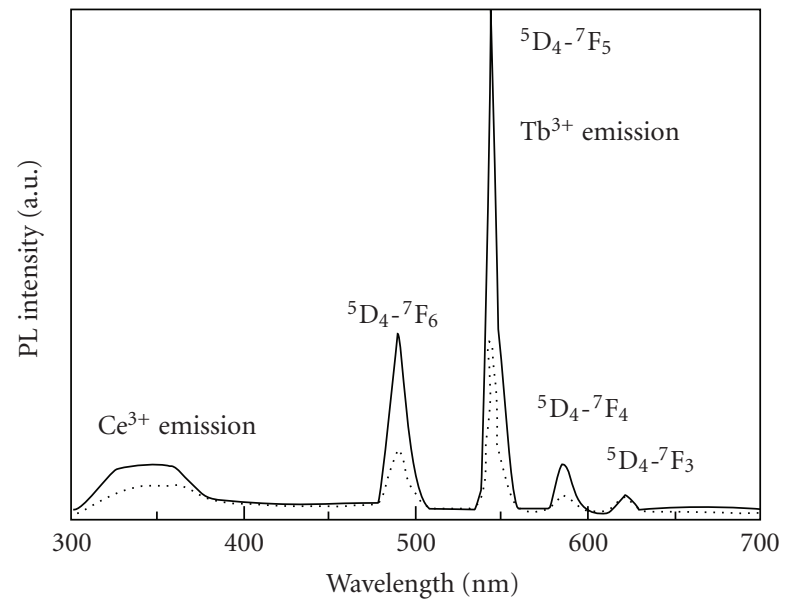

FIgURE 4: Fig. 4 Luminescence emission $\left(\lambda_{\text {ex }}=278 \mathrm{~nm}\right)$ spectra of the dilute colloidal solutions of the $\mathrm{Ce}_{0.9} \mathrm{~Tb}_{0.1} \mathrm{PO}_{4} 1 \mathrm{D}$ nanostructures (dashed line) and the $\mathrm{Ce}_{0.9} \mathrm{~Tb}_{0.1} \mathrm{PO}_{4} @ \mathrm{LaPO}_{4} 1 \mathrm{D}$ nanocable heterostructures (solid). (J. Phys. Chem. B 2008, 109, 14461).

microrods corresponding to the excitation of $\mathrm{Ce}^{3+}$ ions. It should be noted that the emission of $\mathrm{Ce}^{3+}$ or $\mathrm{Tb}^{3+}$ in single-doped nanowires is lower than that in microrods. The dynamic results were listed in Table 2 . The dynamic measurements and analysis indicate that the electronic transition rate of $\mathrm{Ce}^{3+}$ and $\mathrm{Tb}^{3+}$, the ET rate from $\mathrm{Ce}^{3+}$ to $\mathrm{Tb}^{3+}$ in $\mathrm{Ce}^{3+}-\mathrm{Tb}^{3+}$ codoped $\mathrm{LaPO}_{4}$ nanowires, is lower than that in microrods. They attributed the increased intensity of $\mathrm{Tb}^{3+}$ in nanowires to the lower ET efficiency from $\mathrm{Tb}^{3+}$ to other quench centers, shown in Figure 3. According to the $\mathrm{Eu}^{3+}$ and $\mathrm{Tb}^{3+}$ doped LaPO4 nanowires, we suggested that the RE-doped 1D nanowires were ideal nanophosphors. In addition, we also observed the ET from $\mathrm{Gd}^{3+}$ to $\mathrm{Tb}^{3+}$ in $\mathrm{GdPO}_{4}: \mathrm{Tb}^{3+}$ nanorods [48].

\section{The Core Shell Nanostructures of $\mathrm{LaPO}_{4}$ Nanowires Doped with RE}

Due to the increased disorder of surface atoms for nanomaterials, the nonradiative transition rate of RE-doped nanocrystals will increase. The surface modification can effectively eliminate the quenching centers at surface of nanocrystal. In 1999, Li et al prepared $\mathrm{Y}_{2} \mathrm{O}_{3}: \mathrm{Eu}^{3+} @ \mathrm{SiO}_{2} / \mathrm{Al}_{2} \mathrm{O}_{3}$ nanoparticles heterostructures and observed the increase of $\mathrm{Eu}^{3+}$ luminescence [49]. In 2003, Haase prepared the $\mathrm{CePO}_{4}: \mathrm{Tb}^{3+} / \mathrm{Eu}^{3+} @ \mathrm{LaPO}_{4}$ nanoparticles core-shell structures and observed that the quantum yield of $\mathrm{Tb}^{3+}$ was increased from $43 \%$ to $70 \%$ [50, 51]. Lin group systematically studied $0 \mathrm{D}$ nanoparticles doping with RE coated with $\mathrm{SiO}_{2}$ [52-67]. Recently, 1D nanosized core-shell structures doped with $\mathrm{RE}$ have been reported. $\mathrm{Bu}$ et al. reported uniform $\mathrm{CePO}_{4} @ \mathrm{LaPO}_{4}$ and $\mathrm{CePO}_{4}: \mathrm{Tb}^{3+} @ \mathrm{LaPO}_{4} 1 \mathrm{D}$ singlecrystalline nanocable heterostructures with highly enhanced photoluminescent emission [36]. The resulting 1D singlecrystalline nanocable heterostructures have smooth and uniform $\mathrm{LaPO}_{4}$ sheaths, which is of great significance in effectively eliminating surface trap-states and suppressing the energy quenching in ET processes. The photoluminescence results for these 1D nanocable heterostructures illustrate that the uniform $\mathrm{LaPO}_{4}$ sheaths remarkably increase the luminescent efficiency. Figure 4 shows the emission spectra of $\left(\lambda_{\mathrm{ex}}=278 \mathrm{~nm}\right)$ the dilute colloidal solutions of the $\mathrm{Ce}_{0.9} \mathrm{~Tb}_{0.1} \mathrm{PO}_{4}$ 1D nanostructures (dashed line) and the $\mathrm{Ce}_{0.9} \mathrm{~Tb}_{0.1} \mathrm{PO}_{4} @ \mathrm{LaPO}_{4} 1 \mathrm{D}$ nanocable heterostructures (solid lines). It is obvious that the emission intensity of $\mathrm{Tb}^{3+}$ and $\mathrm{Ce}^{3+}$ in $\mathrm{LaPO}_{4}: \mathrm{Ce}^{3+}, \mathrm{Tb}^{3+}$ nanowires coated with $\mathrm{LaPO}_{4}$ is much high than that in noncoated samples.

Fang et al. also reported that $\mathrm{CePO}_{4}: \mathrm{Tb}^{3+} / \mathrm{LaPO}_{4}$ core/shell nanowires synthesized by a simple hydrothermal method, and the resulting 1D core/shell nanostructures have high photoluminescence efficiency [35]. Until recently, it has been considered difficult to obtain a nanocrystal phosphor material with the quantum yield being close to that of the corresponding bulk material. The novel core/shell nanostructures, which are more robust than organically passivated nanowires, may be used as building blocks for optoelectronic nanodevice applications. $\mathrm{CePO}_{4}: \mathrm{Tb} / \mathrm{LaPO}_{4}$ core/shell nanowires with high quantum yield would also be a new class of biomedical labels for ultrasensitive, multicolor, and multiplexing applications owing to their nontoxicity and biocompatibility.

In summary, we introduced the recent progresses of phosphate $1 \mathrm{D}$ nanowires doped with RE. We suggest that the research focus should be the application of $1 \mathrm{D}$ nanowires in biological probe, photonic crystals, optical communication, etc in future.

\section{References}

[1] R. N. Bhargava, D. Gallagher, X. Hong, and A. Nurmikko, "Optical properties of manganese-doped nanocrystals of ZnS," Physical Review Letters, vol. 72, no. 3, pp. 416-419, 1994.

[2] S. B. Qadra, E. F. Skelton, D. Hsu, et al., "Elastic constants and charge ordering in $\alpha^{\prime}-\mathrm{NaV}_{2} \mathrm{O}_{5}$," Physical Review B, vol. 60, no. 13, pp. 9194-9197, 1999.

[3] M. Ihara, T. Igarashi, T. Kusunoki, and K. Ohno, "Cathodoluminescence and photoluminescence of nanocrystal phosphors," Journal of the Electrochemical Society, vol. 149, no. 3, pp. H72-H75, 2002.

[4] C. Donega, A. Bol, and A. Meijerink, "Time-resolved luminescence of ZnS: $\mathrm{Mn}^{2+}$ nanocrystals," Journal of Luminescence, vol. 96, no. 2-4, pp. 87-93, 2002. 
[5] L. Li, C. Tsung, Z. Yang, et al., "Rare-earth-doped nanocrystalline titania microspheres emitting luminescence via energy transfer," Advanced Materials, vol. 20, no. 5, pp. 903-908, 2008.

[6] J. Del-Castillo, V. Rodriguez, A. Yanes, and J. MéndezRamos, "Energy transfer from the host to $\mathrm{Er}^{3+}$ dopants in semiconductor $\mathrm{SnO}_{2}$ nanocrystals segregated in sol-gel silica glasses," Journal of Nanoparticle Research, vol. 10, no. 3, pp. 499-506, 2008.

[7] J. Dhanaraj, R. Jagannathan, T. Kutty, and C. Lu, "Photoluminescence characteristics of $\mathrm{Y}_{2} \mathrm{O}_{3}: \mathrm{Eu}^{3+}$ nanophosphors prepared using sol-gel thermolysis," Journal of Physical Chemistry $B$, vol. 105, no. 45, pp. 11098-11105, 2001.

[8] Z. Wei, L. Sun, C. Liao, C. Yan, and S. Huang, "Fluorescence intensity and color purity improvement in nanosized $\mathrm{YBO}_{3}: \mathrm{Eu}$," Applied Physics Letters, vol. 80, no. 8, pp. 14471449, 2002.

[9] R. S. Meltzer, S. Feofilov, and B. Tissue, "Dependence of fluorescence lifetimes of $\mathrm{Y}_{2} \mathrm{O}_{3}: \mathrm{Eu}^{3+}$ nanoparticles on the surrounding medium," Physical Review B, vol. 60, no. 20, pp. R14012-R14015, 1999.

[10] D. Williams, B. Bihari, B. M. Tissue, and J. McHale, "Preparation and fluorescence spectroscopy of bulk monoclinic $\mathrm{Eu}^{3+}: \mathrm{Y}_{2} \mathrm{O}_{3}$ and comparison to $\mathrm{Eu}^{3+}: \mathrm{Y}_{2} \mathrm{O}_{3}$ nanocrystals," Journal of Physical Chemistry B, vol. 102, no. 6, pp. 916-920, 1998.

[11] K. Hong, R. Meltzer, B. Bihari, D. Williams, and B. Tissue, "Spectral hole burning in crystalline $\mathrm{Eu}_{2} \mathrm{O}_{3}$ and $\mathrm{Y}_{2} \mathrm{O}_{3}: \mathrm{Eu}^{3+}$ nanoparticles," Journal of Luminescence, vol. 76-77, pp. 234 237, 1998.

[12] U. Rambabu, D. Amalnerkar, B. Kale, and S. Buddhudu, "Optical properties of $\mathrm{LnPO}_{4}: \mathrm{Tb}^{3+}(\mathrm{Ln}=\mathrm{Y}, \mathrm{La}$ and $\mathrm{Gd})$ powder phosphors," Materials Chemistry and Physics, vol. 70, no. 1, pp. 1-6, 2001.

[13] J. Dexpert-Ghys, R. Mauricot, and M. Faucher, "Spectroscopy of $\mathrm{Eu}^{3+}$ ions in monazite type lanthanide orthophosphates $\mathrm{LnPO}_{4}, \mathrm{Ln}=\mathrm{La}$ or Eu," Journal of Luminescence, vol. 69, no. 4, pp. 203-215, 1996.

[14] X. Wu, H. You, H. Gui, et al., "Fabrication and characterization of heteroepitaxial bilayers of La-Ca-Mn-O/Y-Ba-Cu-O," Materials Research Bulletin, vol. 37, no. 15, pp. 2531-2538, 2002.

[15] H. Meyssamy, K. Riwotzki, A. Kornowski, S. Naused, and M. Haase, "Wet-chemical synthesis of doped colloidal nanomaterials: particles and fibers of $\mathrm{LaPO}_{4}: \mathrm{Eu}, \mathrm{LaPO}_{4}: \mathrm{Ce}$, and $\mathrm{LaPO}_{4}: \mathrm{Ce}, \mathrm{Tb}, "$ Advanced Materials, vol. 11, no. 10, pp. 840 844, 1999.

[16] L. Yu, H. Song, S. Lu, Z. Liu, L. Yang, and X. Kong, "Luminescent properties of $\mathrm{LaPO}_{4}$ :Eu nanoparticles and nanowires," Journal of Physical Chemistry B, vol. 108, no. 43, pp. 1669716702, 2004.

[17] L. Yu, H. Song, Z. Liu, L. Yang, S. Lu, and Z. Zheng, "Electronic transition and energy transfer processes in $\mathrm{LaPO}_{4}-\mathrm{Ce}^{3+} / \mathrm{Tb}^{3+}$ nanowires," The Journal of Physical Chemistry B, vol. 109, no. 23, pp. 11450-11455, 2005.

[18] H. Song, L. Yu, S. E. Lu, T. Wang, Z. Liu, and L. Yang, "Remarkable differences in photoluminescent properties between $\mathrm{LaPO}_{4}$ :Eu one-dimensional nanowires and zerodimensional nanoparticles," Applied Physics Letters, vol. 85, no. 3, pp. 470-472, 2004.

[19] Y. Fang, A. Xu, R. Song, et al., "Systematic synthesis and characterization of single-crystal lanthanide orthophosphate nanowires," Journal of the American Chemical Society, vol. 125, no. 51, pp. 16025-16034, 2003.
[20] C. Wu, W. Qin, G. Qin, et al., "Photoluminescence from surfactant-assembled $\mathrm{Y}_{2} \mathrm{O}_{3}: \mathrm{Eu}$ nanotubes," Applied Physics Letters, vol. 82, no. 4, pp. 520-522, 2003.

[21] M. Yada, M. Mihara, S. Mouri, M. Kuroki, and T. Kijima, "Rare earth (Er, Tm, Yb, Lu) oxide nanotubes templated by dodecylsulfate assemblies," Advanced Materials, vol. 14, no. 4, pp. 309-313, 2002.

[22] X. Wang and Y. Li, "Rare-earth-compound nanowires, nanotubes, and fullerene-like nanoparticles: synthesis, characterization, and properties," Chemistry - A European Journal, vol. 9, no. 22, pp. 5627-5635, 2003.

[23] M. Yada, C. Taniguchi, T. Torikai, T. Watri, S. Furuta, and H. Katsuki, "Versatile helical polymer films: chiroptical inversion switching and memory with re-writable (RW) and write-once read-many (WORM) modes," Advanced Materials, vol. 16, no. 18, pp. 1448-1450, 2004.

[24] L. Yu, H. Song, Z. Liu, L. Yang, and S. Lu, "Fabrication and photoluminescent characteristics of $\mathrm{La}_{2} \mathrm{O}_{3}: \mathrm{Eu}^{3+}$ nanowires," Physical Chemistry Chemical Physics, vol. 8, no. 2, pp. 303-308, 2006.

[25] X. Bai, H. Song, L. Yu, et al., "Luminescent properties of pure cubic phase $\mathrm{Y}_{2} \mathrm{O}_{3} / \mathrm{Eu}^{3+}$ nanotubes/nanowires prepared by a hydrothermal method," Journal of Physical Chemistry B, vol. 109, no. 32, pp. 15236-15242, 2005.

[26] H. Song, G. Pan, X. Bai, S. Li, H. Yu, and H. Zhang, "One-dimensional rare earth compounds and complexes: preparation and improved photoluminescence properties," Journal of Nanoscience and Nanotechnology, vol. 8, no. 3, pp. 1316-1325, 2008.

[27] H. Yu, H. Song, G. Pan, et al., "Preparation and luminescent properties of $\mathrm{YVO}_{4}$ : $\mathrm{Eu}^{3+}$ nanofibers by electrospinning," Journal of Nanoscience and Nanotechnology, vol. 8, no. 3, pp. 14321436, 2008.

[28] X. Wu, Y. Tao, C. Song, C. Mao, L. Dong, and J. Zhu, "Morphological control and luminescent properties of $\mathrm{YVO}_{4}: \mathrm{Eu}$ nanocrystals," Journal of Physical Chemistry B, vol. 110, no. 32, pp. 15791-15796, 2006.

[29] L. H. Peng, Y. C. Zhang, and Y. C. Lin, "Zinc oxide doping effects in polarization switching of lithium niobate," Applied Physics Letters, vol. 78, no. 1, pp. 4-6, 2001.

[30] X. Duan, Y. Yang, Y. Cui, J. Wang, and C. Lieber, "Indium phosphide nanowires as building blocks for nanoscale electronic and optoelectronic devices," Nature, vol. 409, no. 6816, pp. 66-69, 2001.

[31] Z. Pan, Z. Dai, and Z. Wang, "Nanobelts of semiconducting oxides," Science, vol. 291, no. 5510, pp. 1947-1949, 2001.

[32] Y. Xia and P. Yang, "Chemistry and physics of nanowires," Advanced Materials, vol. 15, no. 5, pp. 351-352, 2003.

[33] M. Haase, K. Riwotzki, H. Meyssamy, and A. Kornowski, "Synthesis and properties of colloidal lanthanide-doped nanocrystals," Journal of Alloys and Compounds, vol. 303-304, pp. 191197, 2000.

[34] K. Riwotzki, H. Meyssamy, A. Kornowski, and M. Haase, "Liquid-phase synthesis of doped nanoparticles: colloids of luminescing $\mathrm{LaPO}_{4}: \mathrm{Eu}$ and $\mathrm{CePO}_{4}: \mathrm{Tb}$ particles with a narrow particle size distribution," Journal of Physical Chemistry B, vol. 104, no. 13, pp. 2824-2828, 2000.

[35] Y. Fang, A. Xu, and W. Dong, "Highly improved green photoluminescence from $\mathrm{CePO}_{4}: \mathrm{Tb} / \mathrm{LaPO}_{4}$ core/shell nanowires," Small, vol. 1, no. 10, pp. 967-971, 2005.

[36] W. Bu, Z. Hua, H. Chen, and J. Shi, "Epitaxial synthesis of uniform cerium phosphate one-dimensional nanocable heterostructures with improved luminescence," Journal of Physical Chemistry B, vol. 109, no. 30, pp. 14461-14464, 2005. 
[37] Z. Wei, L. Sun, C. Liao, J. Yin, X. Jiang, and C. Yan, "Sizedependent chromaticity in $\mathrm{YBO}_{3}$ :Eu nanocrystals: correlation with microstructure and site symmetry," Journal of Physical Chemistry B, vol. 106, no. 41, pp. 10610-10617, 2002.

[38] Z. Wei, L. Sun, C. Liao, et al., "Size dependence of luminescent properties for hexagonal $\mathrm{YBO}_{3}$ :Eu nanocrystals in the vacuum ultraviolet region," Journal of Applied Physics, vol. 93, no. 12, pp. 9783-9788, 2003.

[39] Z. Wei, L. Sun, C. Liao, J. Yin, X. Jiang, and C. Yan, "Fluorescence intensity and color purity improvement in nanosized $\mathrm{YBO}_{3}$ :Eu," Applied Physics Letters, vol. 80, no. 8, p. 1447, 2002.

[40] H. Peng, H. Song, B. Chen, S. Lu, and S. Huang, "Spectral difference between nanocrystalline and bulk $\mathrm{Y}_{2} \mathrm{O}_{3}: \mathrm{Eu}^{3+}$," Chemical Physics Letters, vol. 370, no. 3-4, pp. 485-489, 2003.

[41] H. Song, S. Lu, Z. Liu, and L. Yang, "Influence of shape anisotropy on photoluminescence characteristics in $\mathrm{LaPO}_{4}: \mathrm{Eu}$ nanowires," Chemical Physics Letters, vol. 399, no. 4-6, pp. 384-388, 2004.

[42] H. Peng, H. Song, B. Chen, et al., "Temperature dependence of luminescent spectra and dynamics in nanocrystalline $\mathrm{Y}_{2} \mathrm{O}_{3}: \mathrm{Eu}^{3+}$," Journal of Chemical Physics, vol. 118, no. 7, pp. 3277-3282, 2003.

[43] H. Song, J. Wang, B. Chem, H. Peng, and S. Lu, "Sizedependent electronic transition rates in cubic nanocrystalline europium doped yttria," Chemical Physics Letters, vol. 376, no. 1-2, pp. 1-5, 2003.

[44] J. Hölsä, M. Leskelä, and L. Niinistö, "Sensitization of $\mathrm{Tb}^{3+}$ luminescence with $\mathrm{Ce}^{3+}$ in $\mathrm{LaOBr}: \mathrm{Tb}^{3+}, \mathrm{Ce}^{3+}$," Journal of Solid State Chemistry, vol. 37, no. 3, pp. 267-270, 1981.

[45] D. Jia, W. Jia, X. Wang, and W. Yen, "Quenching of thermo-stimulated photo-ionization by energy transfer in $\mathrm{CaAl}_{4} \mathrm{O}_{7}: \mathrm{Tb}^{3+}, \mathrm{Ce}^{3+}$," Solid State Communications, vol. 129, no. 1, pp. 1-4, 2004.

[46] M. Jose and A. Lakshmanan, " $\mathrm{Ce}^{3+}$ to $\mathrm{Tb}^{3+}$ energy transfer in alkaline earth (Ba, $\mathrm{Sr}$ or $\mathrm{Ca}$ ) sulphate phosphors," Optical Materials, vol. 24, no. 4, pp. 651-659, 2004.

[47] L. Yu, H. Song, Z. Liu, L. Yang, S. Lu, and Z. Zheng, "Remarkable improvement of brightness for the green emissions in $\mathrm{Ce}^{3+}$ and $\mathrm{Tb}^{3+}$ co-activated $\mathrm{LaPO}_{4}$ nanowires," Solid State Communications, vol. 134, no. 11, pp. 753-757, 2005.

[48] L. Yu, D. Li, and M. Yue, "Fabrication and characterization of the photoluminescent properties of $\mathrm{Tb}^{3+}$ doped onedimensional $\mathrm{GdPO}_{4}$ nanorods," Materials Letters, vol. 61, no. 22, pp. 4374-4376, 2007.

[49] Q. Li, L. Gao, and D. Yan, "Effects of the coating process on nanoscale $\mathrm{Y}_{2} \mathrm{O}_{3}: \mathrm{Eu}^{3+}$ powders," Chemistry of Materials, vol. 11, no. 3, pp. 533-535, 1999.

[50] K. Kömpe, H. Borchert, J. Storz, et al., "Green-emitting $\mathrm{CePO}_{4}: \mathrm{Tb} / \mathrm{LaPO}_{4}$ core-shell nanoparticles with $70 \%$ photoluminescence quantum yield," Angewandte Chemie International Edition, vol. 42, no. 44, pp. 5513-5516, 2003.

[51] O. Lehmann, K. Kömpe, and M. Haase, "Synthesis of $\mathrm{Eu}^{3+}$ doped core and core/shell nanoparticles and direct spectroscopic identification of dopant sites at the surface and in the interior of the particles," Journal of the American Chemical Society, vol. 126, no. 45, pp. 14935-14942, 2004.

[52] M. Yu, J. Lin, and J. Fang, "Silica spheres coated with $\mathrm{YVO}_{4}: \mathrm{Eu}^{3+}$ layers via sol-gel process: a simple method to obtain spherical core-shell phosphors," Chemistry of Materials, vol. 17, no. 7, pp. 1783-1791, 2005.

[53] C. Lin, H. Wang, D. Kong, et al., "Silica supported submicron $\mathrm{SiO}_{2} @ \mathrm{Y}_{2} \mathrm{SiO}_{5}: \mathrm{Eu}^{3+}$ and $\mathrm{SiO}_{2} @ \mathrm{Y}_{2} \mathrm{SiO}_{5}: \mathrm{Ce}^{3+} / \mathrm{Tb}^{3+}$ spherical particles with a core-shell structure: sol-gel synthesis and characterization," European Journal of Inorganic Chemistry, vol. 2006, no. 18, pp. 3667-3675, 2006.

[54] C. Lin, D. Kong, X. Liu, H. Wang, M. Yu, and J. Lin, "Monodisperse and core-shell-structured $\mathrm{SiO}_{2} @ \mathrm{YBO}_{3}: \mathrm{Eu}^{3+}$ spherical particles: synthesis and characterization," Inorganic Chemistry, vol. 46, no. 7, pp. 2674-2681, 2007.

[55] H. Wang, C. Lin, X. Liu, J. Lin, and M. Yu, "Fluorescence intensity and color purity improvement in nanosized $\mathrm{YBO}_{3}$ :Eu," Applied Physics Letters, vol. 87, Article ID 181907, 2005.

[56] H. Wang, M. Yu, C. Lin, X. Liu, and J. Lin, "Synthesis and luminescence properties of monodisperse spherical $\mathrm{Y}_{2} \mathrm{O}_{3}: \mathrm{Eu}^{3+} @ \mathrm{SiO}_{2}$ particles with core-shell structure," Journal of Physical Chemistry C, vol. 111, no. 30, pp. 11223-11230, 2007.

[57] D. Kong, M. Yu, C. Lin, X. Liu, J. Lin, and J. Fang, "Sol-gel synthesis and characterization of $\mathrm{Zn}_{2} \mathrm{SiO}_{4}: \mathrm{Mn} @ \mathrm{SiO}_{2}$ spherical core-shell particles," Journal of the Electrochemical Society, vol. 152, no. 9, pp. H146-H151, 2005.

[58] P. Jia, X. Liu, G. Li, M. Yu, J. Fang, and J. Lin, "Sol-gel synthesis and characterization of $\mathrm{SiO}_{2} @ \mathrm{CaWO}_{4}$, $\mathrm{SiO}_{2} @ \mathrm{CaWO}_{4}: \mathrm{Eu}^{3+} / \mathrm{Tb}^{3+}$ core-shell structured spherical particles," Nanotechnology, vol. 17, no. 3, pp. 734-742, 2006.

[59] G. Li, M. Yu, Z. Wang, J. Lin, R. Wang, and J. Fang, "Sol-gel fabrication and photoluminescence properties of $\mathrm{SiO}_{2} @ \mathrm{Gd}_{2} \mathrm{O}_{3}: \mathrm{Eu}^{3+}$ core-shell particles," Journal of Nanoscience and Nanotechnology, vol. 6, no. 5, pp. 1416-1422, 2006.

[60] X. Liu, P. Jia, J. Lin, and G. Li, "Monodisperse spherical core-shell structured $\mathrm{SiO}_{2}-\mathrm{CaTiO}_{3}: \mathrm{Pr}^{3+}$ phosphors for field emission displays," Journal of Applied Physics, vol. 99, no. 12, Article ID 124902, 2006.

[61] P. Jia, X. Liu, M. Yu, Y. Luo, J. Fang, and J. Lin, "Luminescence properties of sol-gel derived spherical $\mathrm{SiO}_{2} @ \mathrm{Gd}_{2}\left(\mathrm{WO}_{4}\right)_{3}: \mathrm{Eu}^{3+}$ particles with core-shell structure," Chemical Physics Letters, vol. 424, no. 4-6, pp. 358-363, 2006.

[62] M. Yu, H. Wang, C. Lin, G. Li, and J. Lin, "Sol-gel synthesis and photoluminescence properties of spherical $\mathrm{SiO}_{2} @ \mathrm{LaPO}_{4}: \mathrm{Ce}^{3+} / \mathrm{Tb}^{3+}$ particles with a core-shell structure," Nanotechnology, vol. 17, no. 13, pp. 3245-3252, 2006.

[63] H. Wang, M. Yu, C. Lin, and J. Lin, "Core-shell structured $\mathrm{SiO}_{2} @ \mathrm{YVO}_{4}: \mathrm{Dy}^{3+} / \mathrm{Sm}^{3+}$ phosphor particles: sol-gel preparation and characterization," Journal of Colloid and Interface Science, vol. 300, no. 1, pp. 176-182, 2006.

[64] G. Li, Z. Wang, M. Yu, Z. Quan, and J. Lin, "Fabrication and optical properties of core-shell structured spherical $\mathrm{SiO}_{2} @ \mathrm{GdVO}_{4}: \mathrm{Eu}^{3+}$ phosphors via sol-gel process," Journal of Solid State Chemistry, vol. 179, no. 8, pp. 2698-2706, 2006.

[65] G. Li, M. Yu, R. Wang, Z. Wang, Z. Quan, and J. Lin, "Fabrication and photoluminescence properties of core-shell structured spherical $\mathrm{SiO}_{2} @ \mathrm{Gd}_{2} \mathrm{Ti}_{2} \mathrm{O}_{7}: \mathrm{Eu}^{3+}$ phosphors," Journal of Materials Research, vol. 21, no. 9, pp. 2232-2240, 2006.

[66] C. Lin, B. Zhao, Z. Wang, et al., "Spherical $\mathrm{SiO}_{2} @ \mathrm{GdPO}_{4}: \mathrm{Eu}^{3+}$ core-shell phosphors: sol-gel synthesis and characterization," Journal of Nanoscience and Nanotechnology, vol. 7, no. 2, pp. 542-548, 2007.

[67] P. Jia, X. Liu, Y. Luo, M. Yu, and J. Lin, "Sol-gel synthesis and characterization of $\mathrm{SiO}_{2} @ \mathrm{NaGd}\left(\mathrm{WO}_{4}\right)_{2}: \mathrm{Eu}^{3+}$ core-shellstructured spherical phosphor particles," Journal of the Electrochemical Society, vol. 154, no. 1, pp. J39-J43, 2007. 

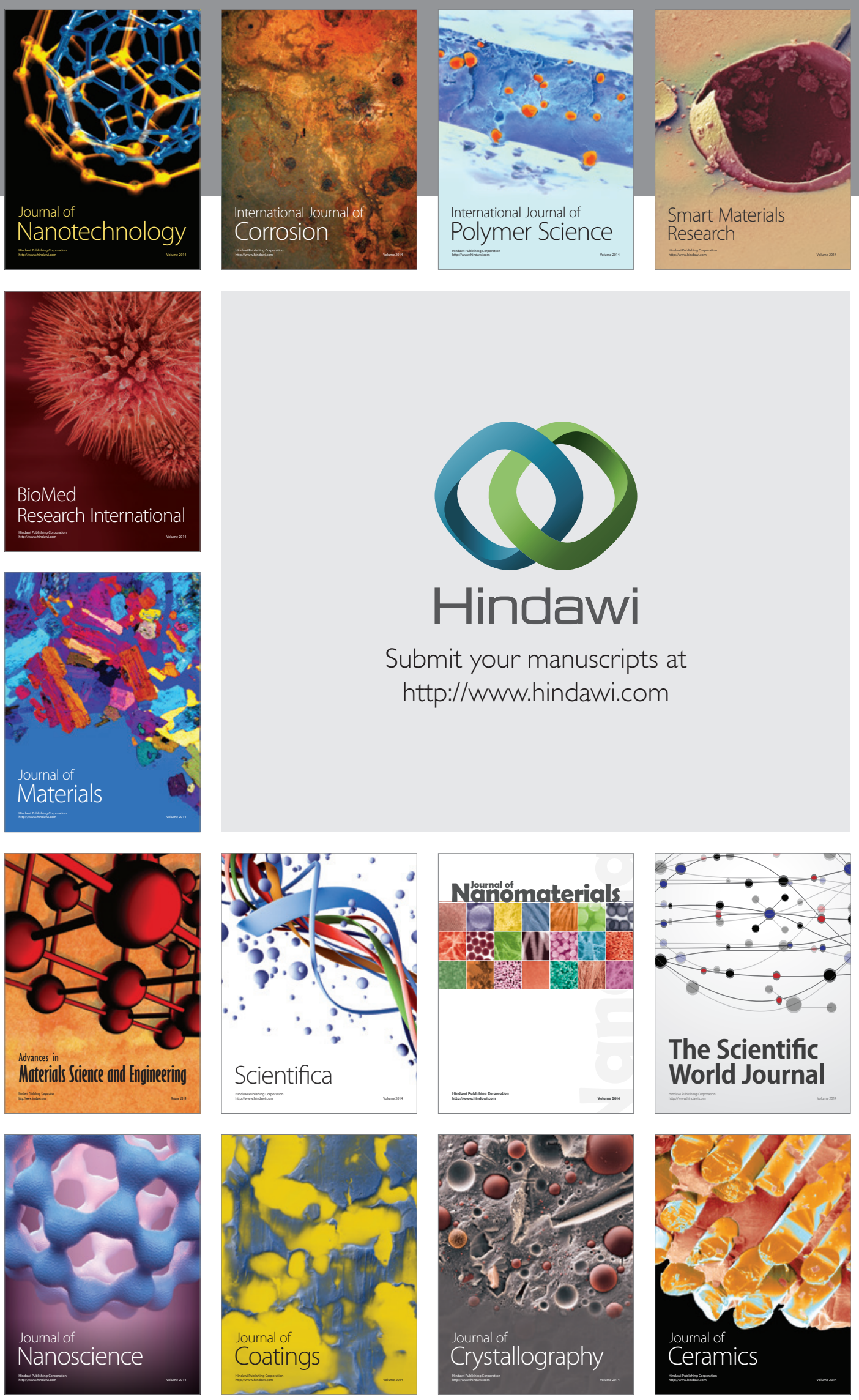

The Scientific World Journal

Submit your manuscripts at

http://www.hindawi.com

\section{World Journal}

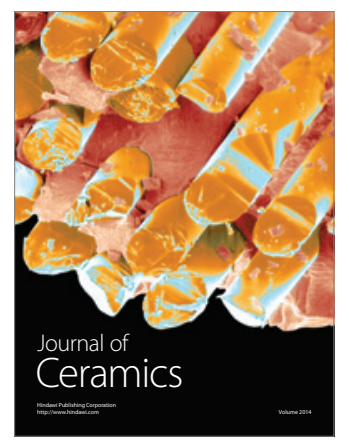

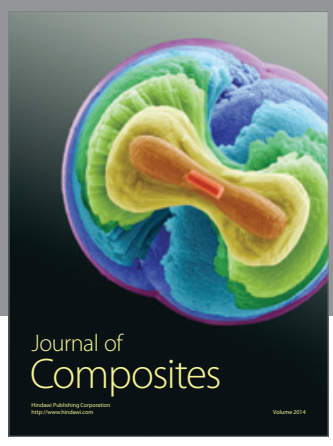
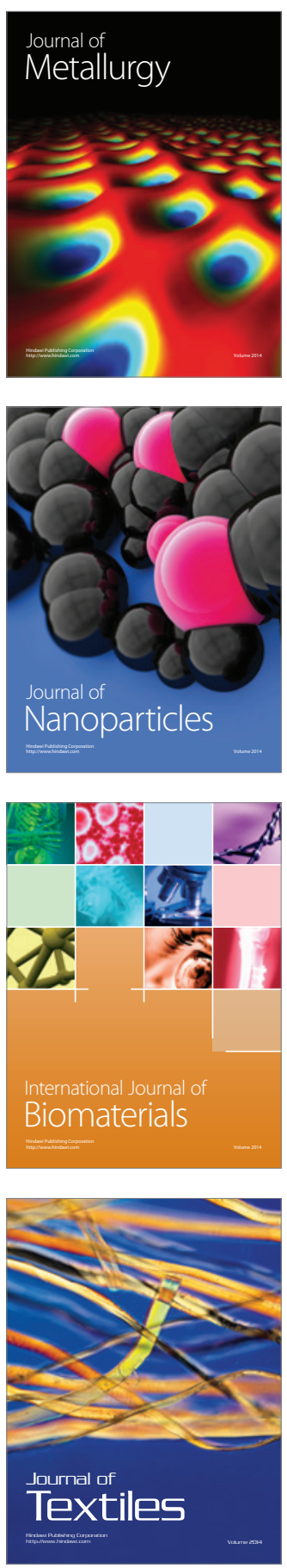